\title{
Influence of Wave Climate on Intra and Inter-Annual Nearshore Bar Dynamics for a Sandy Beach
}

\author{
Nataliya Andreeva ${ }^{1, *(\mathbb{C}}$, Yana Saprykina $\left.{ }^{2}{ }^{(}\right)$, Nikolay Valchev ${ }^{1}\left(\mathbb{D}\right.$, Petya $_{\text {Eftimova }}{ }^{1}$ and Sergey Kuznetsov $^{2}(\mathbb{D}$ \\ 1 Institute of Oceanology, Bulgarian Academy of Sciences, 40 Parvi May Blvd., P.O. Box 152, \\ 9000 Varna, Bulgaria; valchev@io-bas.bg (N.V.); eftimova@io-bas.bg (P.E.) \\ 2 Shirshov Institute of Oceanology, Russian Academy of Sciences, Nahimovskiy Prospekt, 36, \\ Moscow 117997, Russia; saprykina@ocean.ru (Y.S.); kuznetsov@ocean.ru (S.K.) \\ * Correspondence: n.andreeva@io-bas.bg
}

Citation: Andreeva, N.; Saprykina, Y.; Valchev, N.; Eftimova, P.; Kuznetsov, $S$. Influence of Wave Climate on Intra and Inter-Annual Nearshore Bar Dynamics for a Sandy Beach. Geosciences 2021, 11, 206. https://doi.org/10.3390/ geosciences11050206

Academic Editors: Jesus Martinez-Frias and Gianluigi Di Paola

Received: 16 February 2021

Accepted: 5 May 2021

Published: 8 May 2021

Publisher's Note: MDPI stays neutral with regard to jurisdictional claims in published maps and institutional affiliations.

Copyright: (C) 2021 by the authors Licensee MDPI, Basel, Switzerland. This article is an open access article distributed under the terms and conditions of the Creative Commons Attribution (CC BY) license (https:// creativecommons.org/licenses/by/ $4.0 /)$.

\begin{abstract}
The study investigates cross-shore outer sand bar dynamics in an open-coast non-tidal beach at the Bulgarian Black Sea due to wave climate. On seasonal to short-term (1-2 years) time scale, monthly field measurements of the outer bar profiles were related to respective modeled nearshore wave data. Hereby, seaward-shoreward bar migration was examined depending on the wave forcing, wave non-linearity, wave transformation scenarios, storms and direction of wave incidence. Analysis revealed that intra-annually highly non-linear waves were responsible for outer bar displacement, while the direction of migration depended on wave period, duration of conditions with wave steepness $>0.04$, angle of approach and total duration of storms. Short-term bar evolution was mainly governed by wave height and storms' parameters as the angle of approach and duration. The correlation between the outer bar location and wave height annual variations initiated the first for the explored Black Sea region examination of possible connection between wave height's temporal fluctuations and the variability of climatic indices the North Atlantic Oscillation (NAO), the Atlantic Multi-decadal Oscillation (AMO), the East Atlantic Oscillation (EA), the Arctic Oscillation (AO), the East Atlantic-Western Russia (EA/WR) and the Scandinavian (SCAND) patterns. According to the results the inter-annual outer bar location may vary depending on periods of maximum annual wave fluctuations, which in turn predominantly depend on indices the EA (4-5, 10-11, 20-30 years), the EA/WR (2-4, 9-13 years) and the NAO (15 years).
\end{abstract}

Keywords: wave climate; nearshore bars; field data; cross-shore bar migration; wave conditions; wave non-linearity; storms; teleconnection patterns; Black Sea

\section{Introduction}

The nearshore environments of mild-sloped sandy beaches are often characterized by the presence of a variety of morphological features, as most common are sand bars. Typically, they are shore-parallel, crescentic or irregular shoals [1]. Sand bars are often found at depths less than $10 \mathrm{~m}$ and within or just seaward of the surf zone, whose width is influenced by variations in the incident wave climate. Over the years, many mechanisms have been proposed to explain bar formation [2], which eventually were placed into three main groups [3]: breakpoint-related mechanisms [4,5], infra-gravity wave-related mechanisms [6,7] and self-organizational mechanisms [8,9]. The presence of sand bars in the coastal zone is of significant importance for sandy beach morphodynamics since they act as a storage of sediments and as a natural protection by dissipating high wave energy during storms by breaking, thus limiting coastal erosion and flooding hazards [10,11]. These morphological features may exert a significant impact on the nearshore hydrodynamics due to their cross-shore and long-shore geometry and location [12,13]. Moreover, studying the sand bar dynamics allows identification of important physical processes that control coastal evolution, and thus enrich the understanding and knowledge about sediment transport in the coastal zone [14]. 
Nearshore bathymetry varies on a spectrum of time scales ranging from inter-annual (longer than a year) to intra-annual (equal to or shorter than 1 year). Intra-annual time scales include the seasonal cycle and shorter fluctuations associated with passing storms and weak to calm wave conditions [1]. The strong seasonal variability of wind and wave climate drives sandy beaches to exhibit strong seasonal morphodynamic cycles [15]. They are associated with sediments being eroded from the foreshore during high waves, forming storm or winter beach profile [16] followed by recovery during lower energy conditions (swell or summer profile). Typically, these seasonal cycles in beach morphodynamics are reflected in the submerged beach profile with "sandbars building and migrating offshore during storm conditions, and deflating and migrating onshore during low-energy swell conditions" [15]. Cross-shore sand bar migration, resulting in beach profile changes is associated with "imbalance between the cross-shore sediment transport driven by wave non-linearities (orbital velocity skewness and asymmetry), undertow and the gravitational downslope effects" [17]. The offshore sandbar migration is attributed to breaking of large storm waves over the bar with a dominant offshore bed return flow-induced sediment transport. On the other hand, its slow onshore migration takes place in between storms due to a dominant onshore sand transport driven by wave non-linearities during weakly to non-breaking wave regimes across the bar $[17,18]$. Meanwhile, frequent changes in wave intensity may exert minor bar displacements reflecting its relative stability in the nearshore zone [19]. In the last decades the seasonal sandbar migration has been studied using in situ measurements and numerical modeling in $[15,20-25]$. Despite that, the nearshore morphological evolution on seasonal time scales is still poorly understood since field observations have been limited due to difficulties and expense of working in nearshore environments $[15,23]$. Over the years, nearshore morphodynamics on different coastal stretches along the Bulgarian Black Sea coast has been investigated via field measurements and numerical simulations. On inter-annual time scale in [26,27], on seasonal and monthly basis in [28,29], and due to individual storms in [30-35].

The inter-annual variability of sand bar migration has not been sufficiently studied due to lack of long-term continuous field observations in various coastal environments. At present, sand bar migration is much better investigated and understood at the mediumterm time spans, i.e., less than 10 years. It is reported that there are migration cycles (return periods) of about 3-4 years [11,36] and 2-5 years [37]. It is assumed that the decrease of the return period is associated with more energetic wave conditions [36]. According to an analysis of bathymetric data collected for 30 years on the Terschelling coast the long-term evolution of sand bars has characteristic stages: generation, seaward migration and decay, and this cycle has periods up to 10-20 years [38]. Investigations of long-term bar behavior based on nearshore profiles' measurements performed for nearly 30 years along the Holland coast have revealed strong alongshore bar variability [39]. Regions of homogeneous Large-Scale Coastal Behavior (LSCB-regions) controlled by different hydrodynamics, or sediment and morphological structure were selected. The length sizes of the LSCB-regions are from $5 \mathrm{~km}$ up to $42 \mathrm{~km}$. The change between LSCB-regions occurs sharply at distances shorter than $2 \mathrm{~km}$. Such alongshore variability also does not allow determination of clear patterns of long-term variability trends on barred shores. In the model proposed in [40] a short-term (months) dynamical processes in the coastal zone are used to predict medium-term bar displacements. The model reproduces well enough the seaward bar migration, but do not explain bar generation stage, because of the influence of wave climate on the medium-term bar migration and because the nearshore sediment transport is not completely understood.

The first study that has associated the sand bar migration with changes in the climatic indices (the North Atlantic Oscillation in particular) is [41]. They confirmed the existence of such connection based on 15-year time series of Argus video images on the evolution of the submerged profile in the Perranporth beach. In [42], on the example of the Black Sea, it was shown that coastal wave climate is rather heterogeneous and different parts of the coast can correlate in a different manner with variations in the climatic indices, i.e., having 
different periods of long-term fluctuations. This can also cause heterogeneous variability in the bar's migration along the coast.

Thus, the primary objective of the study is to investigate inter- and intra-annual cross-shore outer bar migration and their dependence on the regional wave climate on the example of an open-coast non-tidal beach at the western Black Sea coast. Description of the study site is given in Section 2. Section 3 introduces data sets of beach profile field measurements (Section 3.1), numerically modeled wave forcing (Section 3.2) and their statistical processing. Results are discussed in Section 4. Section 4.1 presents examination of the intra-annual bar evolution on the grounds of variability of wave forcing and nonlinearity, storms and direction of wave incidence. Section 4.2 explores the inter-annual bar evolution and reveals main periods of its middle and long-term variability due to changes in the main climatic indices affecting the wave climate of the coastal region under consideration. The conclusions follow in Section 5.

\section{Study Site}

The study site is located in the southern part of Kamchia-Shkorpilovtsi beach, which is the largest and longest $(\approx 14 \mathrm{~km})$ sandy beach along the Bulgarian Black Sea coast with well-developed dunes and the presence of two rivers-Kamchia and Fandakliyska (Figure 1).

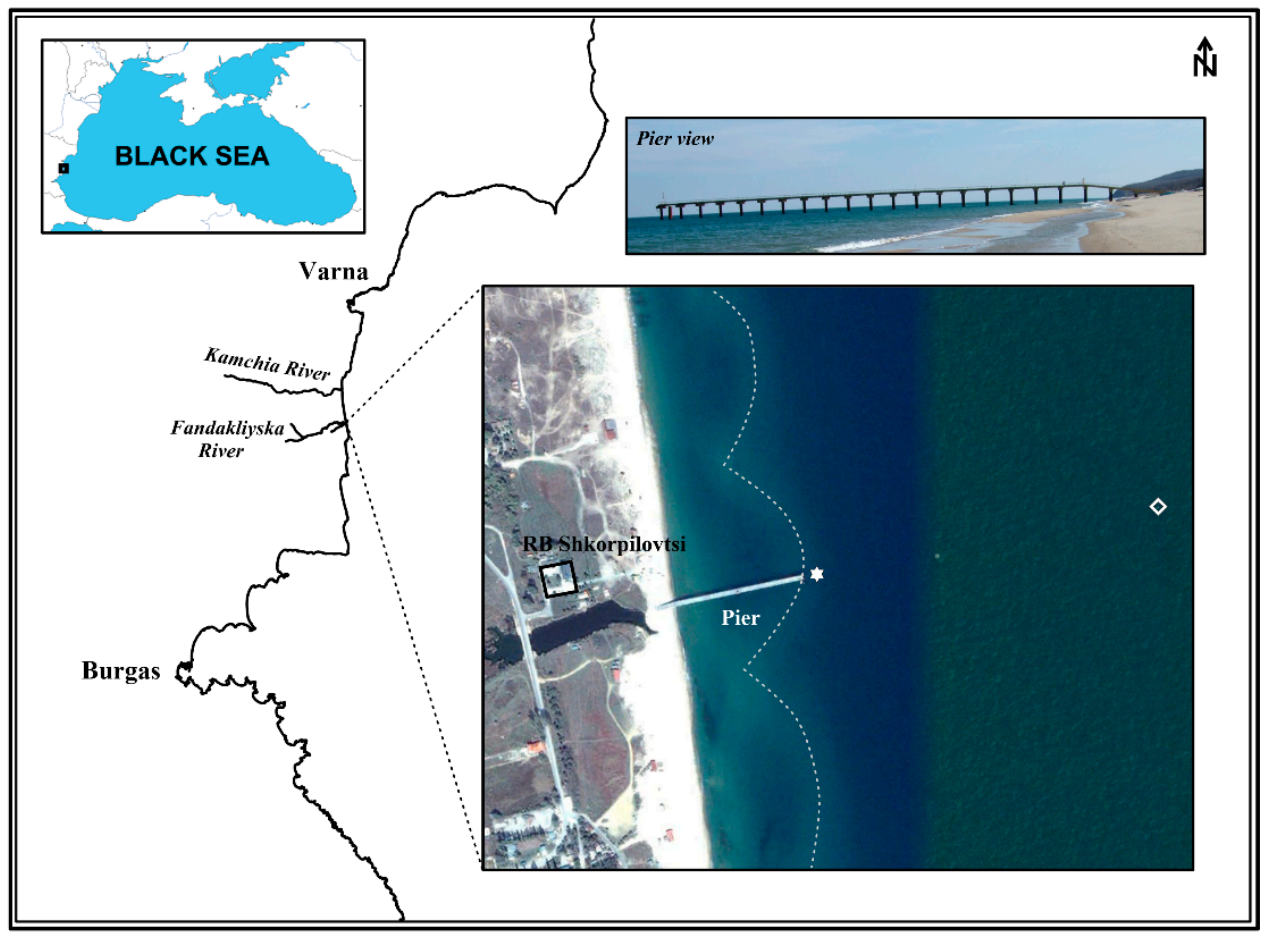

Figure 1. Description and location of the study site. The satellite view shows the location of the field site on the Bulgarian Black Sea coast and indicates the positions of the research station 'Shkorpilovtsi', the pier, and the state of the crescentic bars (dashed grey line) along the coastline on 24th September 2009; white diamond-extraction point of the climatic wave data, depth $17 \mathrm{~m}$; white star-same for wave time series, depth $4.4 \mathrm{~m}$; data sources: the Black Sea basin map was taken from free maps platform [43] and the satellite image was acquired by Maxar Technologies, USA [44].

The coastal area is open to the winds and waves of the eastern half. Strong seasonal variability is the most remarkable feature of the wind and wave climate. Winds from the northeast quarter are the most frequent in the western Black Sea. Having the largest fetch, they trigger the most severe storms. The northeastern winds prevail over the study area. In general, the southeastern winds are less significant in terms of storm intensity. Following the wind pattern waves approach the shore mostly from the northeast, east and 
southeast as the impact of waves coming from northeast and east is much more pronounced. Thus, a large amount of the waves approach the shore in the normal generating intensive cross-shore water circulations as compared to relatively weak long-shore wave-driven currents [45]. Based on wave hindacast data the maximum significant wave height can reach up to $5 \mathrm{~m}$ at depths of about $20 \mathrm{~m}$ [46]. The beach is formed due to the accumulation of erosive and fluvial sediments and has a positive sediment budget since it is constantly fed by sediments from both rivers, as well as from a well-developed ravine and gully system [47]. Morphological conditions of the adjacent coastal zone are rectilinear shoreline with almost parallel isobaths and nearshore crescentic bars (Figure 1).

The study site area near the mouth of Fandakliyska River is equipped with two field research facilities: a research station 'Shkorpilovtsi' and a $230 \mathrm{~m}$-long pier constructed perpendicularly to the shore, thus covering the most dynamic part of the coastal zone $(\approx 200 \mathrm{~m})$. It rises $7 \mathrm{~m}$ above the mean sea level and water depths at its sea-end vary between $4-5 \mathrm{~m}$ (Figure 1). Therein, at depths $0-10 \mathrm{~m}$ the mean slope of the seabed is $0.02-0.025$, while for depths 10-20 $\mathrm{m}$ it is 0.006 [48]. Reflection coefficient estimated for different parts of the shore is of the order of $10^{-2}-10^{-3}$, which means that the reflection of the waves at this dissipative coast has practically no effect on their heights [49]. The shoreface around the pier usually features one inner sand bar at distances 40-60 $\mathrm{m}$ and depths $0.5-2 \mathrm{~m}$ [50] and an outer crescentic sand bar at depths $3-5 \mathrm{~m}$ and distances $110-200 \mathrm{~m}$. On the upper submerged profile (depths $<2.5 \mathrm{~m}$ ), over $95 \%$ of bed sediments are composed of coarse to medium-sized sands $(0.3-0.76 \mathrm{~mm})$, which mostly consist of quartz $(96 \%)$, while the remaining $4 \%$ are represented by fine shell particles $\left(\mathrm{CaCO}_{3}\right)$. As depth grows, their content decreases, and at 8-10 $\mathrm{m}$ depth over $90 \%$ of the sediments consist of particles less than 0.25 $\mathrm{mm}$ in size $[45,47]$.

\section{Materials and Methods}

\subsection{Field Data: Cross-Shore Profiles}

The morphodynamics of the outer bar was analyzed using discrete measurements of beach profile depths collected along the pier. In the last decades, such measurements were made during a number of international field experiments 'Shkorpilovtsi 2007, 2016, 2018' and within the MICORE project in 2008-2010. Each survey extended from a base point marked as zero at the shore-end of the pier out to typical depths of $4-5 \mathrm{~m}$. The base point was a reference marker in the determination of the offshore distance and it does not coincide with elevation zero of the beach profiles. The data were collected with either a metal pole or a rope lot, as both devices have markings at every $10 \mathrm{~cm}$. The accuracy of both measuring methods is approximately commensurable, as reported accuracy for the metal pole is about $10 \mathrm{~cm}$ [51]. The measurements were made at points of known coordinates distanced at every $2 \mathrm{~m}$ by lowering the metal pole (rope lot) from the pier deck. In 2008-2010 measurements were acquired only with the metal pole. In 2007, 2016 and 2018 cross-shore profiles were surveyed on a daily basis for about a month, usually in October [50]. In 2008-2010 measurements were done predominantly once a month [32].

The dataset collected in 2008-2010 was used to study the intra-annual morphodynamics of the outer bar. During these monthly measurements, the summer surveys were less frequent, while in winter the regularity depended primarily on meteorological forecasts, giving preference to calm seas or very weak swell. In total, 33 cross-shore profiles were measured: one profile in November 2008, 25 profiles in January-December 2009, six profiles in January-April 2010, and one profile in August 2010. For this period, the average shoreline position was approx. $29 \mathrm{~m}$ away from the pier base point. The profiles were subjected to additional processing. The mean slope of each profile was determined as $\tan \beta$ [52] taking into account only its submerged part, i.e., from elevation zero down to the last measured depth. Thus, for $2008 \tan \beta=0.034$, while the average $\tan \beta$ for 2009 and 2010 is 0.039 and 0.045 , respectively. Preliminary analysis of the transects revealed that in 2008-2010 the outer bar was localized at distances 130-220 m off the shore at depths $3.5-4.5 \mathrm{~m}$. Having this in mind, profile depths from elevation zero down to a $100 \mathrm{~m}$-offshore distance were 
removed in order to ease the determination of bar characteristics. The remaining data were subjected to smoothing by Moving Average method with factor 5 for correction of potential errors due to applied measuring technique. The smoothed data series were used to define the deepest shoreward point (fore-bar depth) and the shallowest shoreward value (bar crest) in order to isolate its entire form. It should be preliminary commented that offshore distance available for performing cross-shore measurements was limited by the pier's length. Thereby, in some cases, the last measured profile points with the smallest depths were considered as bar crests, e.g., data for March-July 2009. Outer bar characteristics used for analysis of its intra-annual dynamics were bar profile, bar crest offshore distance, depth above the bar crest (bar location depth) and bar height, determined by subtraction of fore-bar depth from the depth above the crest.

\subsection{Modeled Data: Wave Parameters}

Wave fields at the study site were simulated by the SWAN (Simulating Waves Nearshore) Cycle III spectral numerical wave model, which is based on wave action balance equation [53]. The regional wave climate was reconstructed by means of hindcasting for a period of 62 years. More specifically, the available hindcast data for 1948-2006, obtained using wind fields from the regional climate model REMO (Regional Atmosphere Model) [54] were complemented by simulations for 2007-2010 making use of the Global Forecast System's (GFS) analysis winds [55] to encompass the study period. Both sources of wind forcing are based on atmospheric reanalysis of the National Centers for Environmental Prediction (NCEP) having horizontal resolution of $0.5^{\circ}$. The model was run in a non-stationary mode as numerical simulations had 32 frequencies and 36 directional bands. Two nested SWAN regular grids were set to compute the wave fields in the Western Black Sea shelf and nearshore domain off Kamchia-Shkorpilovtsi beach with horizontal resolution of $1 / 30^{\circ}$ and $400 \mathrm{~m}$, respectively. Boundary condition for the SWAN runs were provided by the WAM (Wave Model) output. More details on both models set-up and validation can be found in $[46,56]$. Thus, long-term numerical simulations secured availability of multi-annual time series of various wave parameters with temporal resolution of one hour.

To analyze the role of regional wave climate on the inter-annual outer bar dynamics the annual 99th Quantiles (Q99) of significant wave height Hs and peak period Tp were calculated from 1948-2010 hindcast data for deep water location (depth $52 \mathrm{~m}$ ) in front of the study site. For intra-annual analysis, two data sets were needed. First set served to establish how 2009-2010 wave conditions related to the regional wave climate. Therefore, multi-annual monthly Q99 of Hs and Tp were evaluated based on the full time span of the hindcast, while monthly Q99 of the same parameters were determined only for 2009 and 2010. In both cases the source data for quantiles estimation were extracted for location offshore the pier in a zone of weak transformation of waves at $17 \mathrm{~m}$ depth (Figure 1). Hourly time series of $\mathrm{Hs}, \mathrm{Tp}$ and mean direction of wave propagation $\mathrm{Dm}$ in November 2008-August 2010 were made available to support detailed analysis. The second set of wave data aided assessment of 2009-2010 bar's dynamics in close vicinity to its location. To this end, initial sea states (wave parameters' time series and monthly Q99 values) were transformed from 17 to $4.4 \mathrm{~m}$ depth-a position located at the end of pier (Figure 1). The transformation was performed using the XBeach (eXtreme Beach) model [57] on a cross-shore profile located along the pier on a grid with variable cell sizes and resolution increasing from $7.3 \mathrm{~m}$ at the offshore boundary up to $1 \mathrm{~m}$ at shore. The input boundary conditions were provided from the SWAM modeling and the XBeach model was run in stationary mode without calculation of sediment transport and morphology update. Model output was post-processed to extract significant wave heights Hs, spectral peak wavelengths Lp and wave steepness Hs/Lp. According to recent studies [58] the efficiency of the SWAN model is very high in deep and transitional waters, and it should not be used for shallow water applications. The XBeach, on the other hand, is used for computation of nearshore hydrodynamics, as in stationary mode it resolves physical processes as wave propagation, directional spreading, shoaling, refraction, wave breaking, etc. [57]. The 
preference to work with the 99th quantile of wave parameters was based on the concept that the position of the nearshore bars is closely related to the position of the breaker line(s), which in turn depends on the severity of wave conditions [4]. Thus, when considering the outer bar, it is only expected to be in the breaker zone during severe storms [10], and as pointed out in [59] large offshore waves are required to induce the outer bar into activity and cause significant morphological change.

\section{Discussion of Results}

\subsection{Intra-Annual Sand Bar Evolution}

\subsubsection{Morphodynamics of the Seabed Relief}

As stated in the field site description the nearshore area around the pier features a double bar profile. Bars' morphodynamics over time could be easily traced in a cross-shore plane if presented in chronological order of all field measurements (Figure 2).

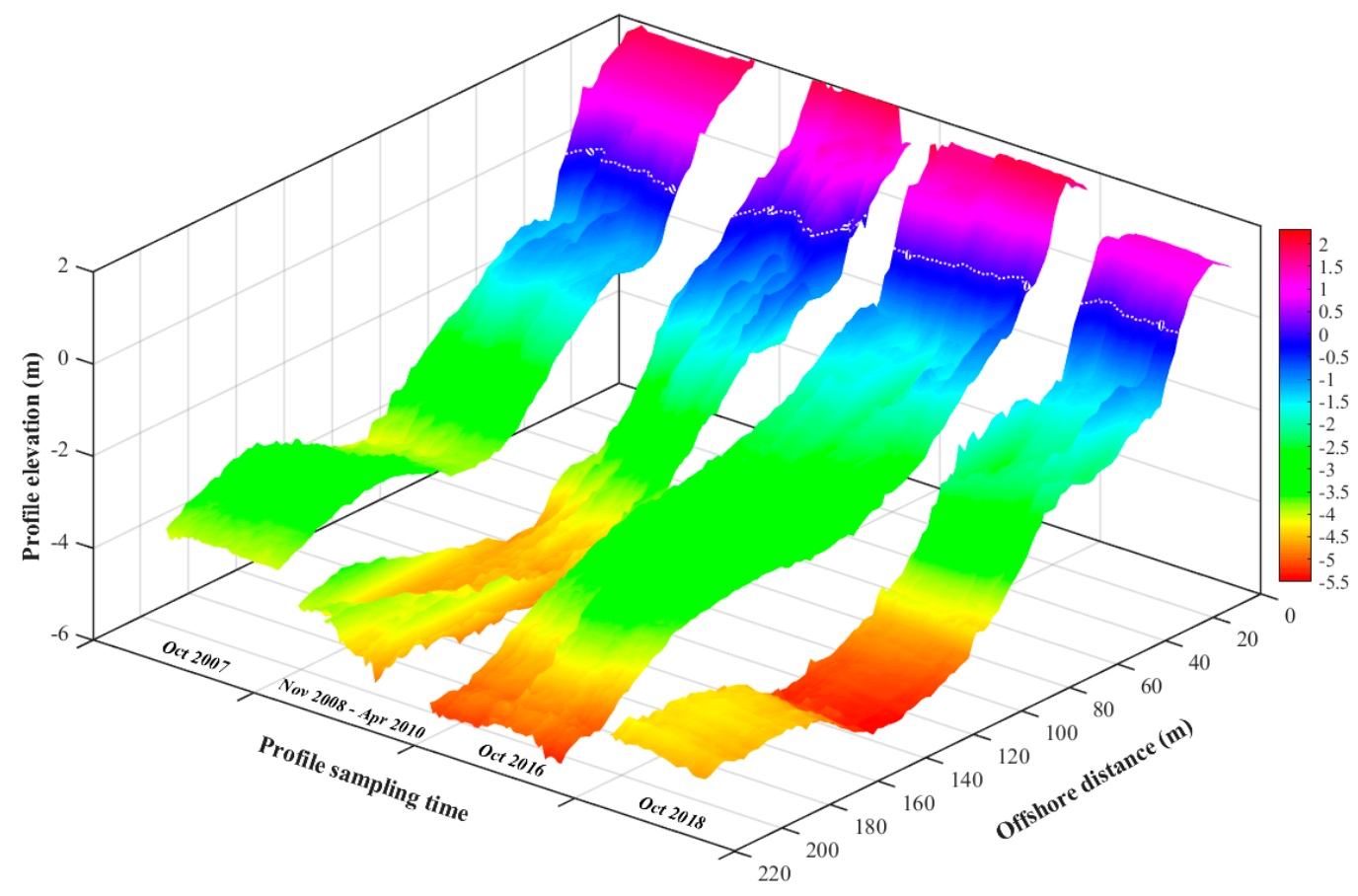

Figure 2. Coastal morphodynamics constructed from cross-shore profile measurements for all field experiments in October 2007, November 2008-April 2010, October 2016 and October 2018 at Kamchia-Shkorpilovtsi beach; white dashed linecontour of the mean sea level.

Considering the surveys in 2007, 2016 and 2018 the inner bar evolution could be observed at offshore distances $40-60 \mathrm{~m}$, as during each of these field campaigns at least one storm event has occurred. In 2008-2010, this zone has widened up to 30-70 m. According to recent studies at the site, the inner bar has a storm origin and commonly exists in the surf zone on a time scale of a few days [60]. Depending on the wave regime, it develops during the storm's initial stage and eventually adjoins the shore while storm attenuates [61]. Analysis of wave and profile data from 2007 and 2016 confirmed the bar formation due to wave breaking by plunging and the combined effect of waves and undertow [50,62], while responsible for its onshore migration are processes of wave breaking switching from plunging to spilling and periodic energy exchange between non-linear wave harmonics [60,62].

The dynamics of the outer bar is quite remarkable, as well (Figure 2). It shows a variability concerning its form, its (a) symmetry, and its offshore and depth location, which is not only inter-annual but annual to seasonal (2008-2010), and even could be observed within a single storm event, as in October 2016. According to the measurements, over the 
years the outer bar is always present, and its evolution and displacement commonly occur within distances of 110-220 m at depths 3-5 m. The closest to the shore the sand bar was in 2007 and 2016 at distances $110-190 \mathrm{~m}$ and 120-210 m, respectively, and it was localized at depths 3-4 m, while in 2018 it was farthermost off the shore at 150-220 m (depths 4-5 m). On the grounds of measurements in 2016, the beach profile deformations were studied during different stages of the reported storm $(\mathrm{Hs} \approx 4.5 \mathrm{~m}$ ), considered as seasonal due to estimated return period of 1 year [61]. The results stated that the outer bar built during the stages of the maximum storm intensity, which led to the formation of a typical storm profile. Storm's attenuation stage, i.e., wave parameters' gradual decrease contributed to the natural process of the beach foreshore recovery, while a slight shoreward shift of the outer bar and increase of the depth above its crest were registered. Based on the same data, $[50,62]$ reported that the growth and displacement of the outer bar depend on the breaking type and location of the breaking zone within the nearshore area. Large storm waves breaking by plunging and wave asymmetry variations with respect to the vertical axis $[63,64]$ trigger initial and further outer bar development, while shifts of the breaking area by plunging entail respective bar crest relocations.

The availability of regular monthly seabed measurements in 2008-2010 gave opportunity for more detailed analysis of the outer bar dynamics on annual and seasonal basis (Figure 3).

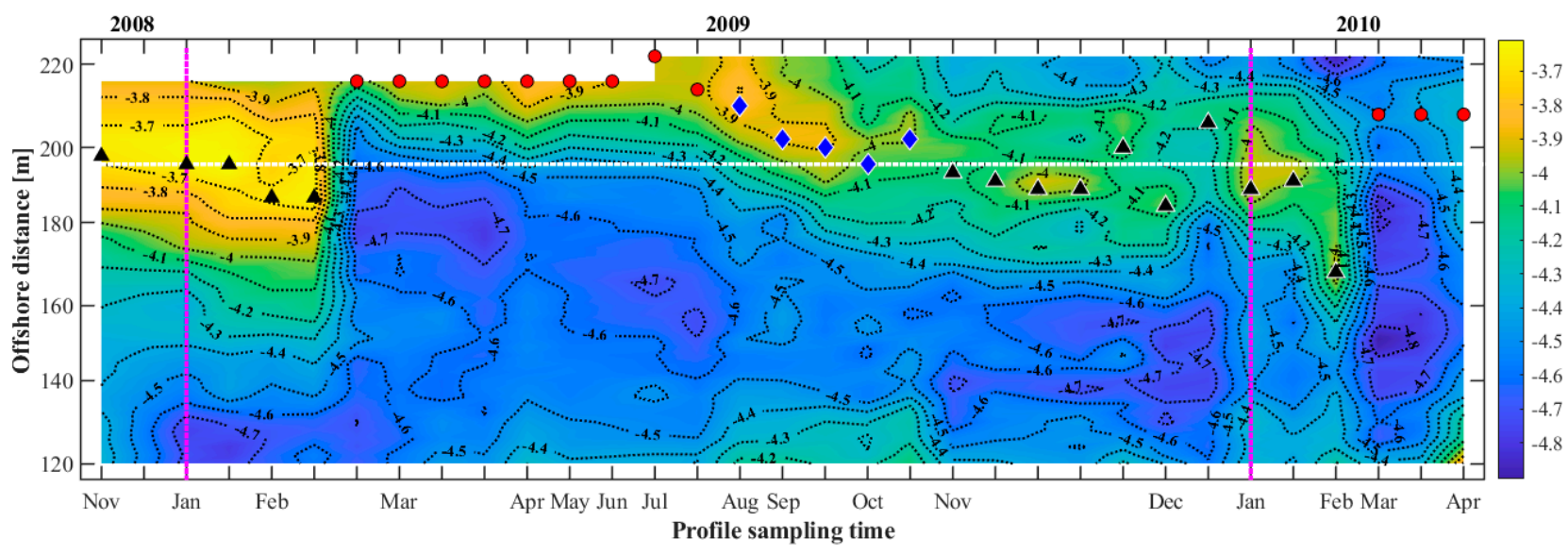

(a)
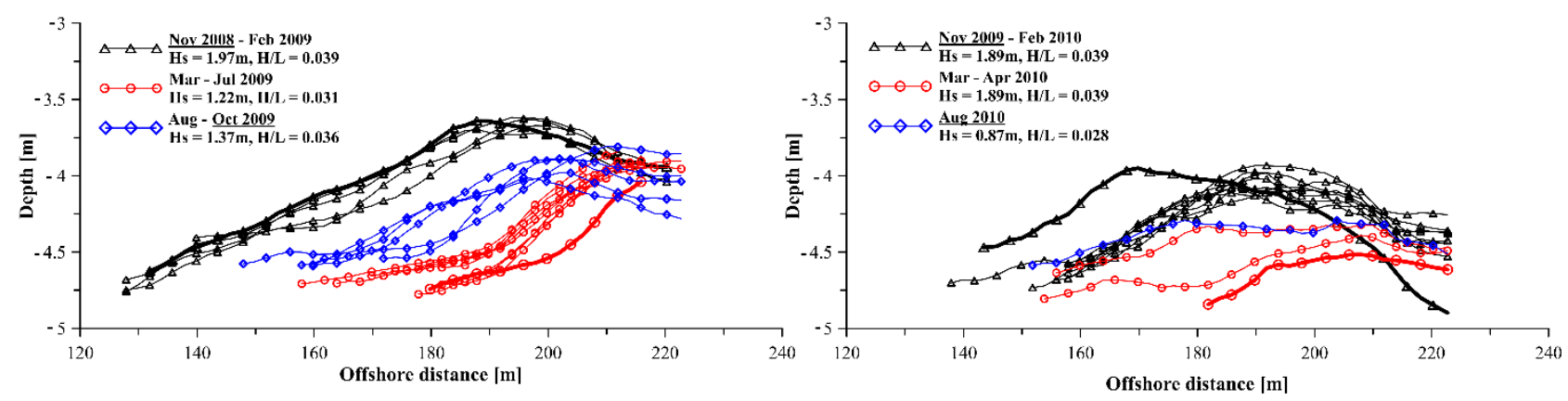

(b)

Figure 3. Intra-annual morphodynamics of the outer sand bar: (a) chronological seabed relief changes in November 2008-April 2010; colors and symbols of bar crest positions correspond to profile groups as described below in the caption text; vertical magenta lines-beginning of each year, horizontal white line-reference winter bar crest location defined from 2009 data; (b) outer bar profile envelopes of temporal variations (sweep zones) for November 2008-October 2009 (left panel) and November 2009-August 2010 (right panel), Hs and H/L-seasonally averaged monthly maximum values of the parameters at depth $4.4 \mathrm{~m}$; black lines with triangles—winter pro-files, red lines with circles-summer profiles, and blue line with diamond-transitional profiles; heavy black line with triangles-last measured profile prior to the abrupt seaward bar shift, heavy red line with circles—-first profile after the bar's displacement to its summer location. 
As previously mentioned, during this period the sand bar migrated within depths $\approx 3.5-4.5 \mathrm{~m}$ and offshore distances $130-220 \mathrm{~m}$. Changes of bed relief and crest positions show that the outer bar's intra-annual variations followed a certain repetitive seasonal pattern (Figure 3a). It was characterized by the bar's presence closer to the shore in winter at distances 180-200 $\mathrm{m}$ followed by an abrupt seaward shift to larger depths at distances $\approx 210-220 \mathrm{~m}$ for spring-summer season, and again a gradual return to its winter location.

It was evident that such bar crest dynamics was accompanied by changes in the bar's form (Figure 3b). After inspection of the measured transects in November 2008-August 2010 and taking into account the seasonal pattern, three groups of profiles were determined according to their similarity in shape:

- Winter profiles, corresponding to sand bar shoreward location in November 2008 (2009)-February 2009 (2010);

- Summer profiles, corresponding to its farthermost positions offshore as in March-July 2009 and March-April 2010;

- Transitional profiles, representing the gradual bar displacement (August-October 2009 and August 2010) back to its winter position in the nearshore zone.

The proposed "winter-summer" distinction is rather based on the seasonality of the outer bar profile evolution discussed herein, than on the classical concept of seasonal beach profiles-winter and summer ones [16]. Moreover, the possibility to distinguish the group of transitional profiles is connected with the wave regime seasonality in general, which is not an abrupt transition from summer low-energy regimes to winter high-energy ones, but rather a process of gradual wave energy increase in a form of a series of subsequent storms [65].

In the first seasonal cycle of bar migration in November 2008-October 2009 (Figure 3b, left panel) each of the introduced profile groups is very easily distinguished, keeping relatively uniform slightly asymmetric shapes in comparison to the next season in November 2009-August 2010. Regardless of its slight cross-shore migration the bar remains relatively high, as its height varies between $0.99-0.66 \mathrm{~m}$ without significant change of its location depth from $\approx 3.6 \mathrm{~m}$ to $\approx 3.9 \mathrm{~m}$ (Table 1 ).

Table 1. Outer bar average characteristics for different profile groups for November 2008-August 2010.

\begin{tabular}{|c|c|c|c|c|c|c|}
\hline \multirow{2}{*}{$\begin{array}{c}\text { Profile Type } \\
\text { Seasons }\end{array}$} & \multicolumn{2}{|c|}{ Winter Profiles } & \multicolumn{2}{|c|}{ Summer Profiles } & \multicolumn{2}{|c|}{ Transitional Profiles } \\
\hline & Nov 2008-Feb 2009 & Nov 2009-Feb 2010 & Mar-Jul 2009 & Mar-Apr 2010 & Aug-Oct 2009 & Aug 2010 \\
\hline Bar crest average offshore distance (m) & 193 & 191 & 217 & 208 & 202 & $204^{1}$ \\
\hline Bar crest average depth $(\mathrm{m})$ & 3.65 & 4.02 & 3.91 & 4.4 & 3.92 & $4.29^{1}$ \\
\hline Average bar height $(\mathrm{m})$ & 0.99 & 0.6 & 0.78 & 0.35 & 0.66 & $0.29^{1}$ \\
\hline
\end{tabular}

${ }^{1}$ Real profile characteristics for August 2010.

During the second seasonal cycle in November 2009-August 2010 (Figure 3b, right panel; Table 1), regardless of partial availability of data, it is evident that the pattern of intra-annual bar evolution is being repeated, but from shoreward shifted location of origin. Even though, only the winter profiles are relatively uniform in shape, generally all profiles are more symmetric. At the beginning of the second cycle, the initial average bar height was $0.60 \mathrm{~m}$ and as the repetition of migration pattern proceeded the offshore bar relocation was accompanied by significant bar crest erosion, thus, increasing the average depth above the crest to $4.4 \mathrm{~m}$. A common feature for both seasonal cycles is that in winter the sand bar has larger heights than in spring-summer season.

\subsubsection{Bar Evolution due to Wave Parameters and Non-Linearity}

The initial steps to analysis of the annual and seasonal bar evolution were to examine the dependence between bar crest locations in 2009-2010 and wave parameters such as significant wave height Hs, peak period Tp and wave steepness Hs/Lp (Figure 4). 

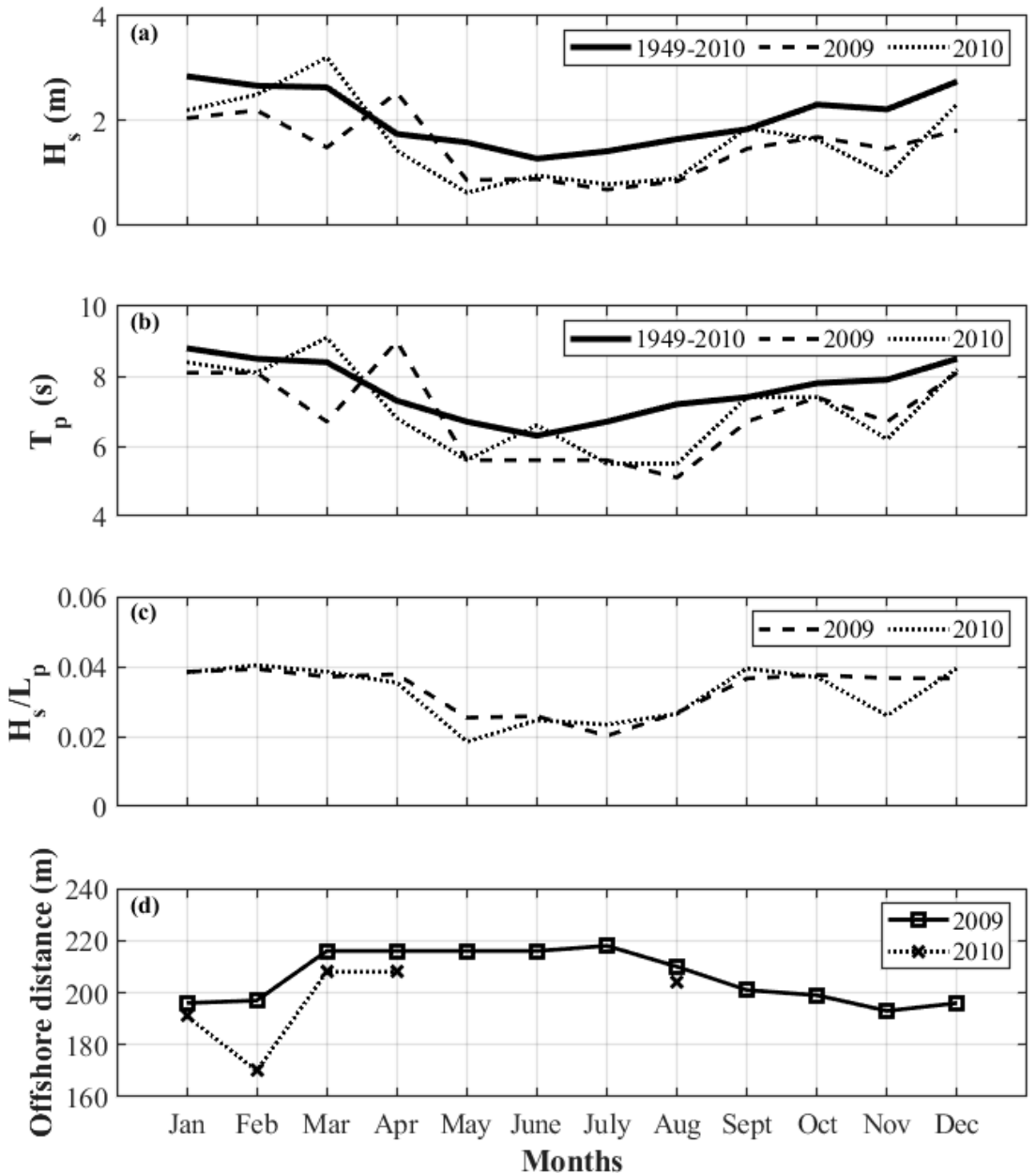

Figure 4. Intra-annual variations of: $(\mathbf{a}, \mathbf{b})$ monthly Q99 of significant wave heights Hs and peak periods Tp for 2009-2010 vs. annual monthly Q99 of the same parameters for 1948-2010 at depth $17 \mathrm{~m}$; (c) wave steepness of transformed monthly Q99 waves for 2009-2010 at depth $4.4 \mathrm{~m}$; (d) average monthly positions of the outer bar crests for 2009-2010.

The analysis comprised an estimate of 2009-2010 wave conditions in comparison to the regional wave climate and whether either of the years was more energetic than the others. To this end, monthly Q99 of Hs and Tp for 2009-2010 were compared to the same annual monthly Q99 for 1948-2010 (Figure 4a,b). Results show that in general, 2009-2010 wave parameters do not exceed the climatic ones. Exceptions concerning wave height are higher estimates for April 2009 and March 2010, and a commensurate value for September 2010. Wave periods follow the same tendency plus higher estimates for June 2010. As for the comparison between the years 2009 and 2010, it appears that on average wave heights are commensurable (1.5 $\mathrm{m}$ in 2009 vs. $1.61 \mathrm{~m}$ in 2010), but a bit longer wave periods (7.1 s) were present in 2010 as oppose to those in 2009 (6.9 s).

The comparison also shows that bar crest position depends on variations of all wave parameters throughout the year. It keeps the same displacement pattern during both years and a clear dependence is seen not only on wave height, but also on wave period and steepness. Winter storms with larger wave heights (periods) and Hs $/ \mathrm{Lp} \approx 0.04$ erode the profile moving the sand bar offshore (Figures 3 and $4 \mathrm{~d}$ ). Summer storms with lower heights (periods) and Hs / Lp $<0.03$ are not capable to induce shoreward bar migration, which is done in the autumn when steepness again increases up to 0.04 . Thus, as per Figure $4 \mathrm{~d}$ in November-February 2009 (same for 2010) the bar crests are found at distances 195-200 m, while at the end of the season the bar is moved offshore $(\approx 220 \mathrm{~m})$ and remains stable 
during March-July 2009 and March-April 2010. Shoreward bar's shift toward its winter location was initiated by storms in August-October 2009 and August 2010.

It is of interest to further examine which values of wave steepness (Hs/Lp) correspond to the positions of the bar crest in the coastal zone. For that purpose, crest offshore distances were set against steepness values of the transformed monthly Q99 waves for 2009-2010 (Figure 5).
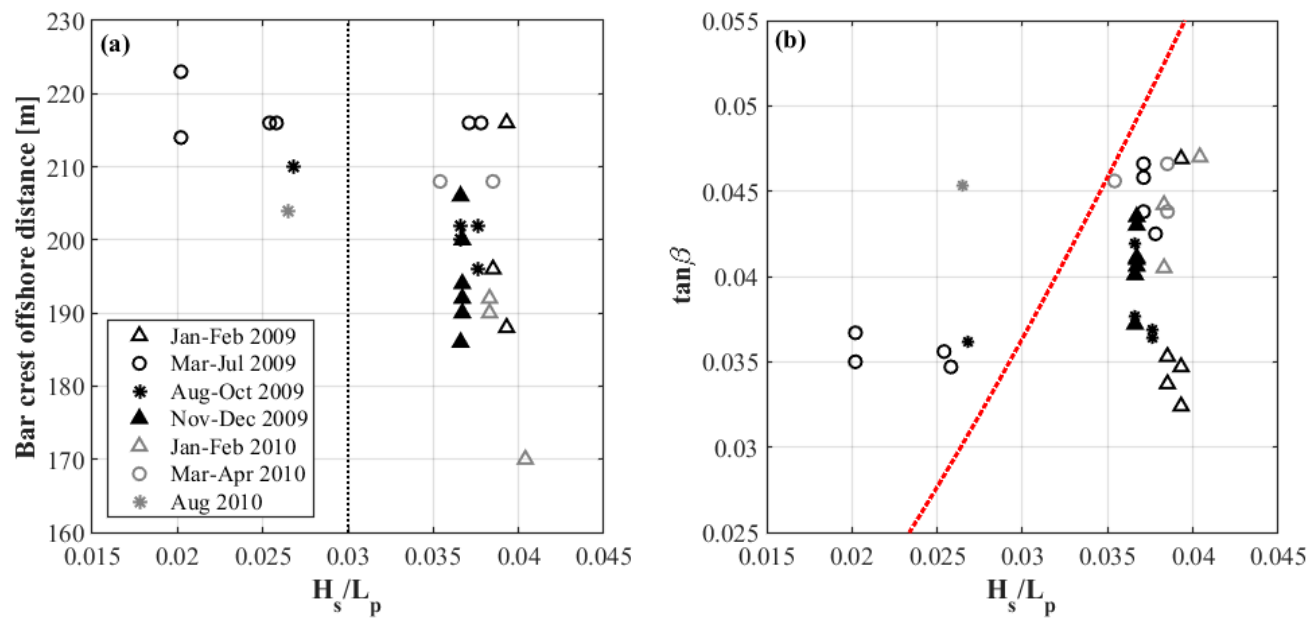

Figure 5. Dependence of steepness Hs/Lp of transformed monthly Q99 waves (depth $4.4 \mathrm{~m}$ ) for 2009-2010 on (a) the offshore distances of the outer bar crest, black dashed line-wave steepness threshold, and (b) the mean slope $\tan \beta$, red dashed line-criterion for identification of non-linear wave transformation scenarios $\left[\tan \beta=7(\mathrm{Hs} / \mathrm{Lp})^{3 / 2}\right.$ ]; black symbols-2009 values, grey symbols2010; circles—seaward bar crest positions, triangles—shoreward bar crest locations, stars—bar crest displacements.

According to the presented results steepness 0.03 could be introduced as a threshold to support differentiation between bar's stable position and its relocations within the nearshore area. Thus, for Hs/Lp < 0.03, as in summer months May-August 2009 and August 2010, the sand bar was stable and located offshore, while for Hs / Lp $\geq 0.035-0.04$ the bar crest was found either offshore $(\approx 220 \mathrm{~m})$ or closer to the coastline, or migrating within distances 170-210 m (Figures 3 and 4). Additionally, wave steepness for JanuaryFebruary 2009 (same for 2010) was higher than for November-December 2009 due to lower wave heights at the end of 2009.

As next, it was necessary to examine for which steepness values the bar remains stable or is subjected to displacement. Another parameter affecting wave steepness and non-linear evolution of waves in the coastal zone is the mean slope $(\tan \beta)$. Depending on the Irribaren number, non-linear wave transformation may proceed by four characteristic scenarios [49]. The scenarios are distinguishable for the periodicity of wave energy exchange between the first and the second non-linear harmonics, as the slope affects the number of periodic cycles and the growth of the second harmonics, which in turn influence the sediment transport along the profile [60].

Using the criterion for realization of the scenarios [49] a dependence was sought between the wave steepness and the mean slope (Figure 5b). As per criterion, for mean slope $\tan \beta>7(\mathrm{Hs} / \mathrm{Lp})^{3 / 2}$ waves in the nearshore zone transform by either of two scenarios, i.e., amplitudes of the second harmonics grow only very close to the shore (S1) or remain small along the entire coastal zone (S3). Results in (Figure 5b) state that for waves in May-August 2009 and in August 2010 scenarios S1 and S3 are applicable. According to the hindcast data these waves have $\mathrm{Hs} / \mathrm{Lp}<0.03$, the average monthly $\mathrm{Hs}$ varies within 0.67-0.86 $\mathrm{m}$ and the average monthly Tp is between 5.1-5.6 s. Based on 2007 field data, the influence of scenario S3 on the morphology of the submerged profile was explored in [60] on a case of a wave regime with significant height $0.6 \mathrm{~m}$ and peak period $\approx 5 \mathrm{~s}$ measured at 
the pier's end. These results confirm the validity of a wave parameters' range introduced above. Moreover, for this scenario only the inner bar profile was subjected to deformations and significant shoreward relocation, while changes on the outer bar were minor. Thus, absence of large second harmonics and spatially small periods of energy exchange dictate weak non-linearity of waves over the outer bar, which contributes to its relative stability in the spring-summer months.

On the other hand, for $\tan \beta<7(\mathrm{Hs} / \mathrm{Lp})^{3 / 2}$ wave transformation proceeds according to one of the other two scenarios, i.e., amplitudes of the second harmonics reach their maxima within the coastal zone (S2) or second harmonics already have large amplitudes upon entering the coastal zone (S4). Such highly non-linear scenarios are valid for data pairs in January-April 2009 and September 2009-April 2010 (Figure 5b). According to hindcast data, steepness of these waves varies between $0.035-0.04$, the average monthly Hs: $1.48-2.12 \mathrm{~m}$ and the average monthly Tp: 6.7-9.1 s. Once again on the basis of 2007 field data, the influence of scenario S2 on the evolution of the submerged beach profile was studied in $[60,62]$ for a wave regime with significant height $1.1 \mathrm{~m}$ and period $7 \mathrm{~s}$ measured at the pier's end. They established that at the length of each full period of energy exchange between the first and the second non-linear harmonics erosion occurs on the seaward bar's slope with sediments being transferred to its shoreward front either for the inner or the outer bar. Furthermore, if the contribution of the undertow and the transition from S2 to S3 is considered, such periodic energy exchange can lead to bar's significant shift toward the shore and changes in its symmetry [60].

To draw a more precise conclusion about the waves capable to act on the bar's stability or displacement, threshold values for $\mathrm{Hs}$ and $\mathrm{Tp}$ were determined by setting the monthly Q99 Hs and Tp (depth $4.4 \mathrm{~m}$ ) against the bar crest offshore distances. This resulted in definition of $\mathrm{Hs} \approx 1 \mathrm{~m}$ and $\mathrm{Tp} \approx 6 \mathrm{~s}$. Having this in mind, it was assumed that waves responsible for cross-shore bar migration transform according to scenarios S2 or S4 and have steepness $>0.03, \mathrm{Hs}>1 \mathrm{~m}$ and peak periods over $6 \mathrm{~s}$.

Therefore, it might be suggested that the summer profiles and the relevant bar's stability are aided and contributed by the influence of weakly non-linear waves (scenarios S1 or S3), while winter and transitional profiles, as well as bar's migration are governed by strong non-linearity of waves represented by scenarios S2 or S4.

Next in line was to examine whether any combination of wave parameters render influence on the bar's movement. To this end, we considered the distribution of bar crest positions against the average monthly data of Hs, Tp and Hs/Lp (depth $4.4 \mathrm{~m}$ ) for January 2009-August 2010. In addition, a reference bar crest distance of $196 \mathrm{~m}$ was determined, based on the most frequent profile measurements in winter 2009 (Figure 3a). The comparison showed that in January-April 2009 and September 2009-April 2010 for similar wave steepness values $\approx 0.04$ the bar crest was localized either close or away from the shore with regard to the reference line (Figure 3a). As for the other wave parameters, it became evident that to a narrow interval of steepness values $(0.035-0.04)$ corresponded a wide range of wave heights: $1.48-2.12 \mathrm{~m}$, respectively periods: $6.7-9.1 \mathrm{~s}$. Despite the time scale discrepancy in the compared data, it was concluded that regardless of the similar steepness values waves that cause the bar crest to shift seaward are higher and with longer periods than those moving it in the opposite direction, which is especially valid for January-April 2009 (2010)—Figures 3a and 4. However, these general findings do not justify in completion the observed intra-annual bar evolution. This implied the necessity to investigate the influence of individual storms and their characteristics on the cross-shore bar crest relocations during January-April 2009 and September 2009-April 2010.

\subsubsection{Influence of Storms and Wave Incidence Angle on Bar Dynamics}

The analysis was based on hourly time series (SWAN model output transformed to $4.4 \mathrm{~m}$ depth) of parameters Hs, Tp and Hs/Lp for November 2008-August 2010, which were chronologically collated with bar crest positions. It was obvious that discrepancies in the temporal resolution of modeled and measured data introduce difficulties in definition 
of direct causal connection between particular wave events and monthly measurements of the bar profiles with pre- or post-storm identity. Therefore, we applied the thresholds for scenarios with strong non-linearity ( $\mathrm{Hs}>1 \mathrm{~m}, \mathrm{Tp}>6 \mathrm{~s}$ and $\mathrm{Hs} / \mathrm{Lp}>0.03$ ) to the time series in order to identify individual storms or sequences of storms that might be claimed responsible for the cross-shore bar migration.

Application of the thresholds showed that in summer months of 2009-2010 waves corresponded to scenarios S1 and S3 and wave conditions caused minor changes to bar height at its farthermost position at $\approx 220 \mathrm{~m}$ (Figure 3). However, influenced by the first autumn storms in September 2009 having characteristics valid for scenarios S2\&S4 $(\mathrm{Hs} \approx 1.5 \mathrm{~m}, \mathrm{Tp} \approx 6.5 \mathrm{~s}, \mathrm{Hs} / \mathrm{Lp} \approx 0.04)$, the sand bar began to move towards the shore reaching its reference location of $196 \mathrm{~m}$ in November 2009. The following storm events (Hs $\approx 1.5-2 \mathrm{~m}, \mathrm{Tp} \approx 7-9 \mathrm{~s}, \mathrm{Hs} / \mathrm{Lp}>0.04$ ) caused minor back-and-forth bar crest shifts of 10-15 $\mathrm{m}$. This state retained up to mid-storm season (January-February), when a storm occurred causing the bar crest initial shoreward displacement. For 2009, such a storm was in January, while for 2010 in February (Figure 3b). The subsequent heavy storm: in February for 2009 $(\mathrm{Hs}>2 \mathrm{~m}, \mathrm{Tp} \approx 8 \mathrm{~s}, \mathrm{Hs} / \mathrm{Lp} \approx 0.04)$ and in March for $2010(\mathrm{Hs} \approx 2.2 \mathrm{~m}, \mathrm{Tp} \approx 9 \mathrm{~s}, \mathrm{Hs} / \mathrm{Lp} \approx$ 0.045 ) caused the maximum bar crest offshore shift to its spring-summer location increasing significantly the depth above the crest (Figure 3a,b; Table 1).

Such approach contributed to the definition of individual storms that were deemed responsible for the shoreward/seaward shifts of the bar (Table 2). The hourly time series for each storm or sequence of storms were additionally processed, keeping for analysis only the data fulfilling the thresholds for non-linear scenarios, i.e., Hs $>1 \mathrm{~m}, \mathrm{Tp}>6 \mathrm{~s}$ and $\mathrm{Hs} / \mathrm{Lp}>0.03$. Afterwards, wave parameters of each storm were averaged to a single value in order to make a comparison between wave steepness values, significant wave heights and peak periods for each storm group (Table 2).

Table 2. Average wave parameters fulfilling the thresholds for scenarios S2\&S4 for storms responsible for outer bar displacements.

\begin{tabular}{ccccc}
\hline Storm Groups (SG) & Hs (m) & Tp (s) & Hs/Lp & $\begin{array}{c}\text { Duration of Wave Conditions } \\
\text { with Hs/Lp }>\mathbf{0 . 0 4} \text { (h) }\end{array}$ \\
\hline $\begin{array}{c}\text { SG1: Storms moving the outer bar shoreward (January } \\
\text { 2009, September-October-November 2009, January 2010) } \\
\text { SG2: Storms moving the outer bar seaward (February } \\
\text { 2009, December 2009, February-March 2010) }\end{array}$ & 1.59 & 6.7 & 0.036 & 66 \\
\hline
\end{tabular}

It appeared that in 2009-2010 storm conditions for each group were rather similar, although waves in SG2 are slightly higher, steeper and with longer periods. The importance of wave height and period for shore profile changes at the site were studied by means of numerical modeling in $[66,67]$. They revealed that the typical scenario of wave action on the beach profile regardless of the season is characterized by erosion near the shoreline and accumulation of sediments seaward. The general trend is that the higher the storm waves and longer the periods the larger the shoreline erosion and the further the seaward accumulation of sediments. For same storm waves with shorter periods, the sediments move closer to the shore. However, a significant difference was noticed concerning the time duration of wave conditions for which Hs/Lp exceeded 0.04 (Table 2). For storms causing bar's seaward shift (SG2) these conditions lasted as twice longer (121 h) as those moving the bar closer to the coast $(66 \mathrm{~h})$. This suggests that not only steepness and wave period should be taken under consideration in analysis of bar behavior but the duration of these conditions as well.

To examine the role of wave incidence angle on bar migration hourly time series of mean direction of wave propagation Dm (depth 17 m) for November 2008-August 2010 were used. As previously, the time series were subjected to the threefold criterion for scenarios S2\&S4 to analyze only the data fulfilling these conditions on three time scales:

- $\quad$ Storm season, November 2008-April 2009 and September 2009-April 2010; 
- $\quad$ Storm groups, as per Table 2;

- Monthly storms, here, three months with the most severe wave conditions were selected from each storm group SG1\&SG2.

Results are presented in Figure 6 using rose charts for each time scale.
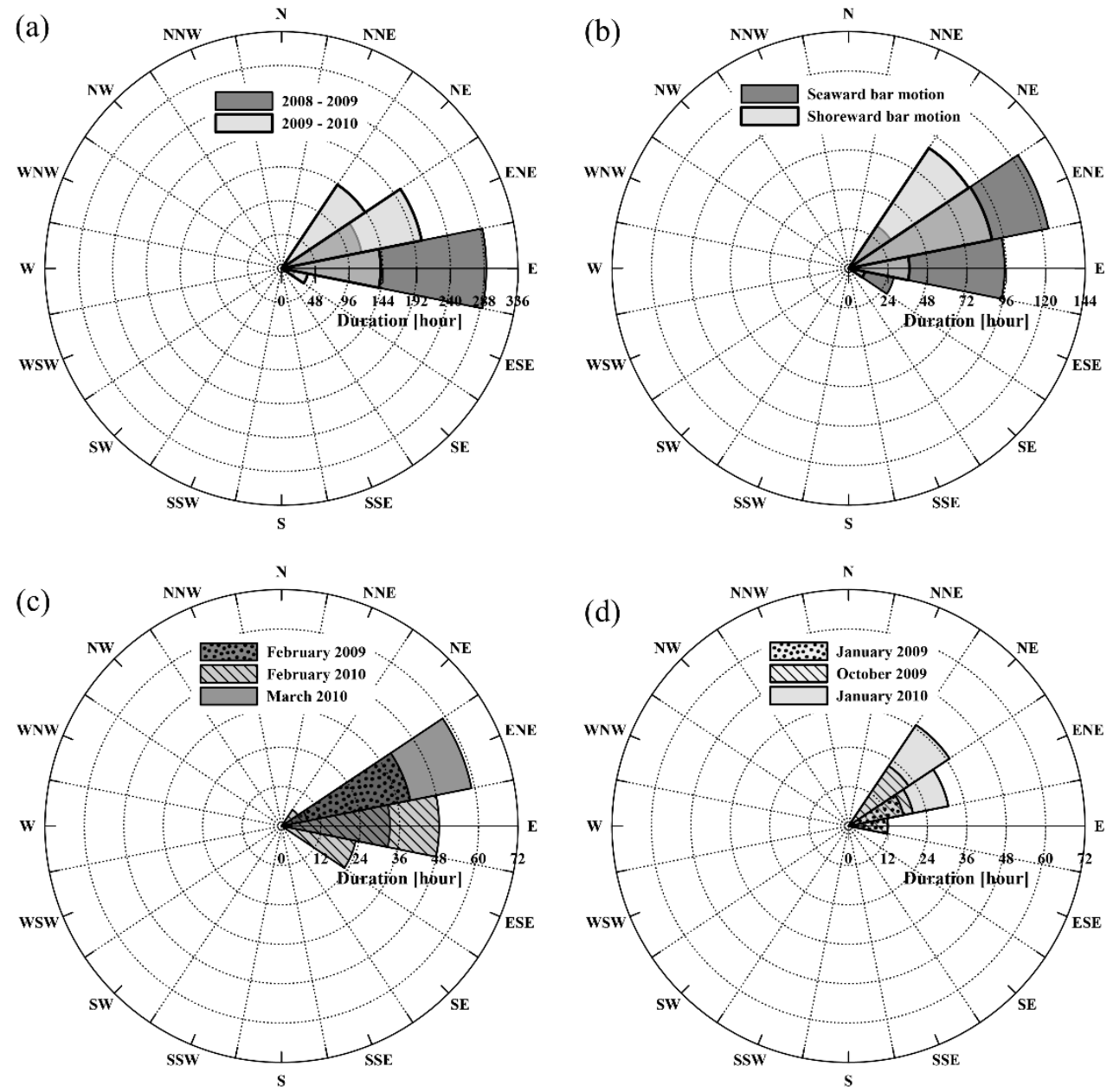

Figure 6. Rose charts of mean direction of wave propagation for: (a) storm seasons; (b) storm groups SG1\&SG2; (c) strongest storms moving the outer bar seaward; (d) strongest storms moving the outer bar shoreward.

During season 2008-2009 (Figure 6a), waves predominantly were approaching in normal to the shore (E-ENE), while in 2009-2010 oblique incidence dominated (NE-ENE). So, for the present case an assumption was made that waves coming at an angle to the coast contribute to bar being moved shoreward due to the presence of long-shore currents, while those approaching in the normal move the bar seaward, mainly governed by non-linear transformation of waves, when they propagate to the coast. Confirmation was found in results concerning the other two time scales. For Storm groups (Figure 6b) waves displacing the bar shoreward have a more oblique approach (NE-ENE) than those moving it seaward. The assumption was verified at the time scale Monthly storms (Figure $6 \mathrm{c}, \mathrm{d}$ ) because storms causing bar shoreward displacement have a distinct NE approach as opposed to storms moving it seaward (ENE to ESE).

Another factor affecting the outer bar movements is the duration of storms. For both time scales Storm groups and Monthly storms (Figure $6 \mathrm{~b}-\mathrm{d}$ ) the storms coming from NEENE and moving the bar shoreward have shorter durations than the storms approaching from E-ENE and shifting the bar offshore. These duration differences do not exceed 20-30\%, which means that the impact of storms balance the bar's cross-shore migration during the 
winter season, causing the bar crest to move back-and-forth with respect to the reference distance of $196 \mathrm{~m}$ (Figure 3a). As for the time scale Storm seasons results show (Figure 6a) that for season 2009-2010, when the dominant direction of wave approach was NE-ENE the duration is $17.7 \%$ longer than the duration in season 2008-2009. These findings were also considered with regard to displacements of the bar crest (Figure 3a). To this end, we determined the maximum cross-shore offsets of the crest from its reference distance. The analysis showed that for storm season 2008-2009 bar's seaward offset is larger $(19.87 \mathrm{~m})$ than its offset to the shore $(8.24 \mathrm{~m})$. An opposite situation was detected for storm season 2009-2010, when bar's seaward offset equals $11.93 \mathrm{~m}$, while its shoreward displacement is $26.17 \mathrm{~m}$. Therefore, the predominance of oblique wave approach and the longer storm duration in 2009-2010 may have caused the shift of the bar's evolution pattern toward the shore in 2010 (Figure 4d).

Thus far, it may be concluded that intra-annual outer bar evolution follows a seasonal pattern of cross-shore migration, which is mainly governed by scenarios of transformation of highly non-linear waves, and the direction of its off/onshore displacement depends on wave period, duration of wave conditions with steepness $>0.04$, angle of wave approach and total duration of storms. Annual bar evolution, on the other hand, depends on wave height and storm's parameters as angle of approach and duration.

\subsection{Possible Periods of Inter-Annual Outer Bar Evolution due to Variations of Wave Climate}

According to analysis in Section 4.1, the location of the outer sand bar predominantly depends on variations of 99th Quantile of the significant wave heights (Q99Hs). As presented in Figure 4 for different years (2009 and 2010) annual variations of bar location depend on the annual variations of Q99Hs, i.e., whether maximum waves were higher or smaller throughout a given year. The fluctuations in wave heights and wave climate depend on wind conditions (wind climate), the variations of which depend on teleconnection patterns determined through the values of the corresponding climatic indices.

Based on long-term data for the Black Sea it was revealed in $[68,69]$ that on a large time scale the indices the Atlantic Multi-decadal Oscillation (AMO), the North Atlantic Oscillation (NAO) and the East Atlantic-Western Russia (EA/WR) have significant influence on the fluctuations of maximum annual wave heights. On a decadal time scale and less, variations of maximum annual wave heights might depend on the NAO, the Arctic Oscillation (AO), the EA/WR, the East Atlantic Oscillation (EA) and the Scandinavian (SCAND) patterns $[68,70-72]$.

In order to determine any periodicity in variations of the maximum annual wave height analysis was conducted to reveal a connection between temporal fluctuations of the Q99Hs and variations of the main climatic indices for the Black Sea study region. The following indices were considered: the NAO, the AMO, the EA, the AO, the EA/WR and the SCAND. Their dimensionless values were taken from the National Oceanic and Atmospheric Administration (NOAA) of the USA [73]. Variations of the Q99Hs for a deep-water point (depth $55 \mathrm{~m}$, Figure 1) offshore the study site and selected climatic indices are shown in Figure 7.

Results show that the maximum annual wave height fluctuates in time around a mean value of $3.04 \mathrm{~m}$. The analysis did not reveal any significant linear trend toward decrease or increase of wave height in time. Minimum wave height was found to be $2.04 \mathrm{~m}$, while the maximum was equal to $4.28 \mathrm{~m}$.

Wavelet analysis by the Morlet wavelet function, representing the temporal evolution of frequency spectrum shows that fluctuations of the maximum annual waves have nonstationary nature (Figure 8, upper panel). Frequency interval 0.08-0.2 [1/year] is of a particular interest, since trends for both increase and decrease were observed therein. Additionally, fluctuations of amplitudes (Figure 8, lower panel) vary in time, as well. Most stable are the temporal variations in frequency interval 0.05-0.03 [1/year] corresponding to periods of 20-30 years. However, there is an insignificant trend toward decrease of fluctuation frequency in time. 

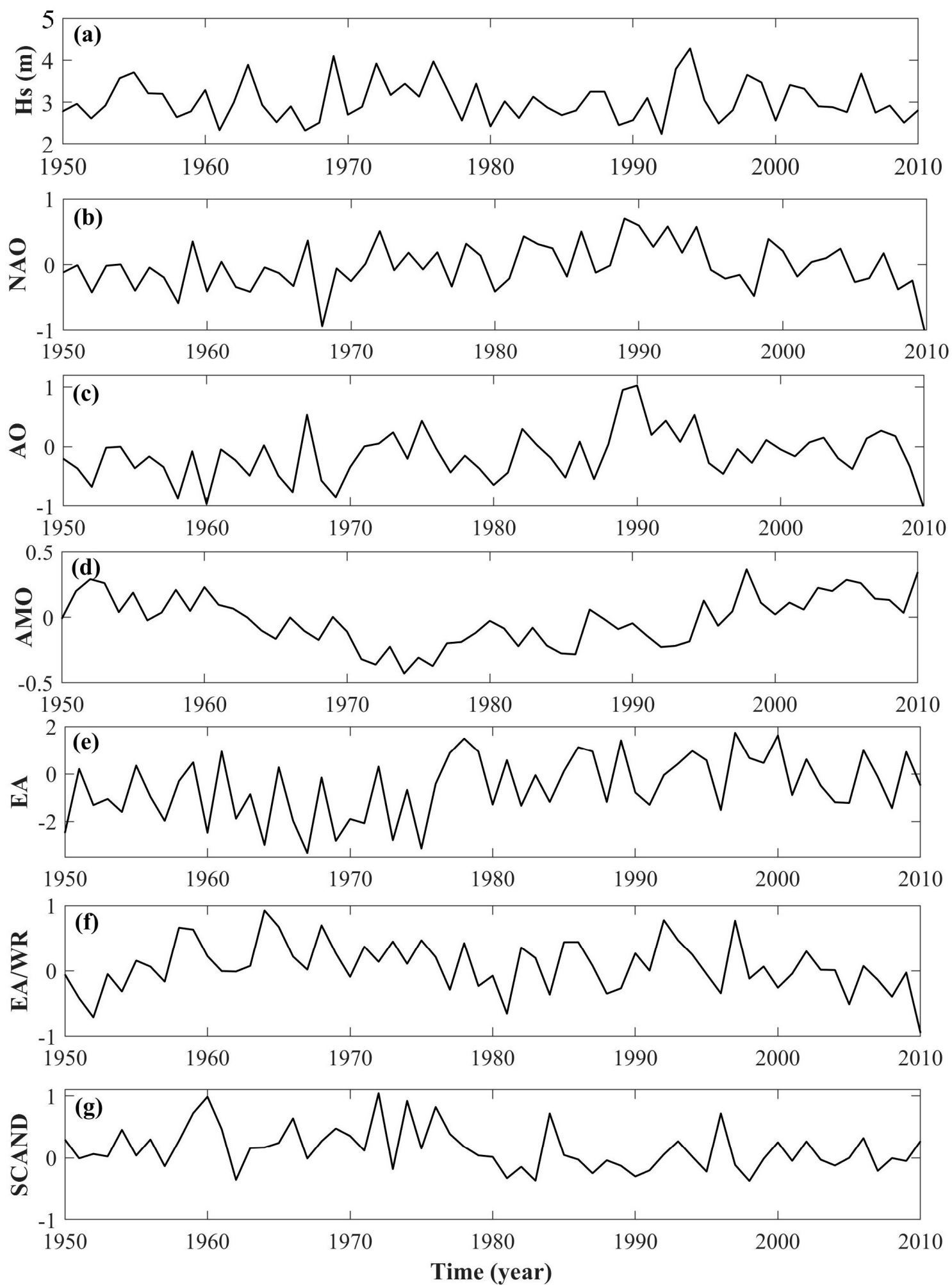

Figure 7. Variations of (a) 99th quantile of the significant wave height and (b) the North Atlantic Oscillation (NAO), (c) the Atlantic Multi-decadal Oscillation (AMO), (d) the East Atlantic Oscillation (EA), (e) the Arctic Oscillation (AO), (f) the East Atlantic-Western Russia (EA/WR) and (g) Scandinavian (SCAND) patterns for 1950-2010. 


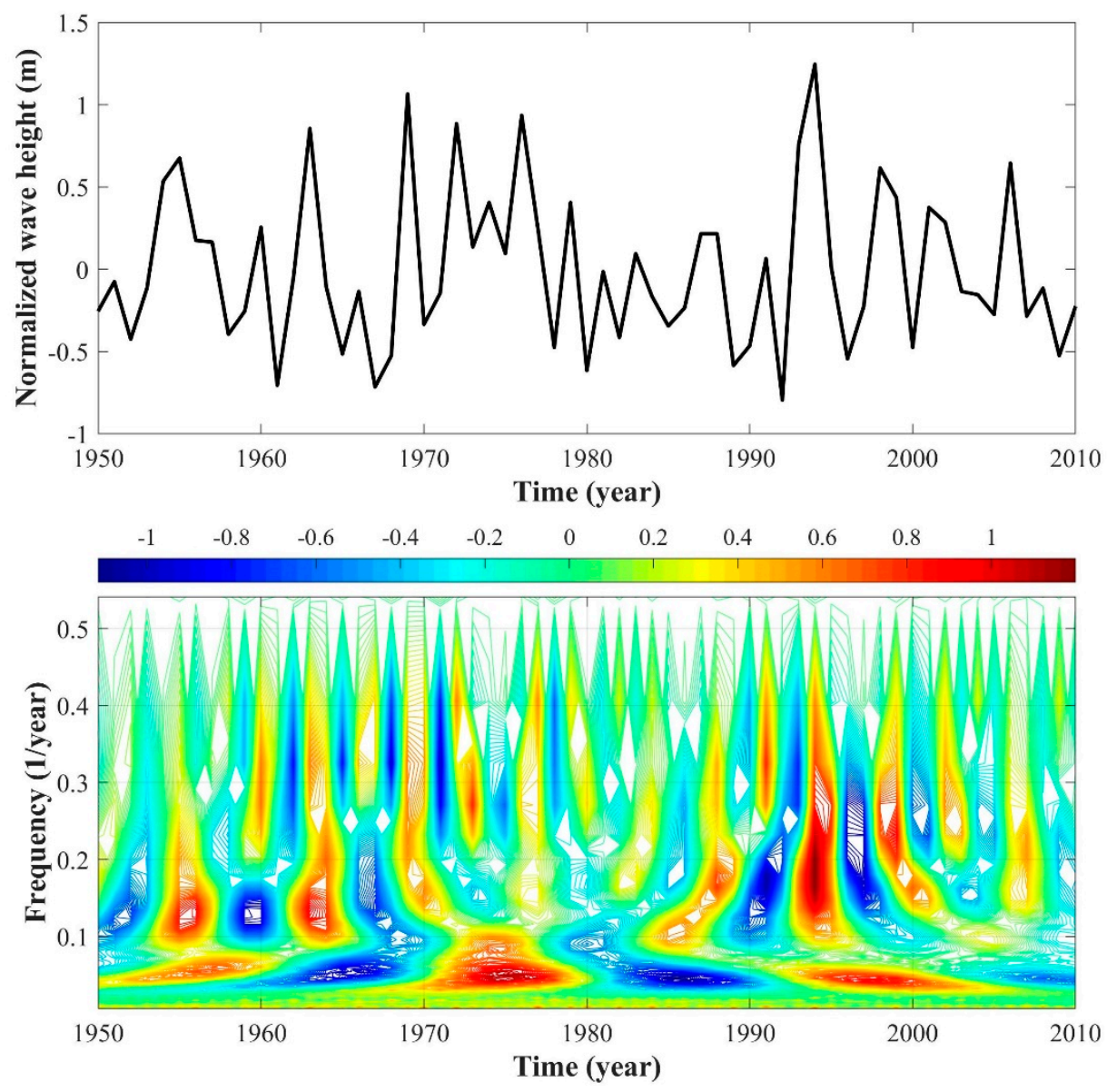

Figure 8. Fluctuations of normalized maximum annual wave time series (mean multi-annual was removed) (upper panel) and wavelet transformation (lower panel).

A previous study by [68] has shown that fluctuations of climate indices are also nonstationary, which makes it impossible to apply the classic correlation analysis to determine the relation between them and the wave height variations. However, a methodology to correlate two non-stationary process based on wavelet analysis was developed in [68,72]. According to this method, mutual correlation functions were calculated between the same frequency scales of two wavelet decompositions, which gives the advantage of having both correlation coefficients and frequencies, where these coefficients have the largest values.

Wavelet correlation coefficients (with time lag $=0$ ) of the maximum wave height variations for selected climate indices are presented in Figure 9. If one considers that correlation coefficient $>0.4$ represents good correlation between geophysical processes, then for large (multi-decadal) time spans of 20-30 years variations of wave heights depend on indices the EA and the SCAND, respectively. Fluctuations corresponding to 10-15 years depend on the EA/WR (9-13 years), the EA (10-11 years), the AMO (13 years), the NAO (15 years) and the $\mathrm{AO}$ (15-16 years). There are also fluctuations of the order of few years that depend on the EA (4-5 years), the EA/WR (4 years), the AMO/AO (3 years), the SCAND and the EA/WR (2 years).

According to the presented analysis, it may be suggested that the Q99 of the wave climate in the coastal region under study at all time spans would be influenced the strongest by the EA and the EA/WR climate indices. Additionally, strong influence might be expected due to variations of indices the AMO, the AO and the SCAND. Significant correlation was established for the NAO index (0.5), but only for variations with time span of 15 years. 


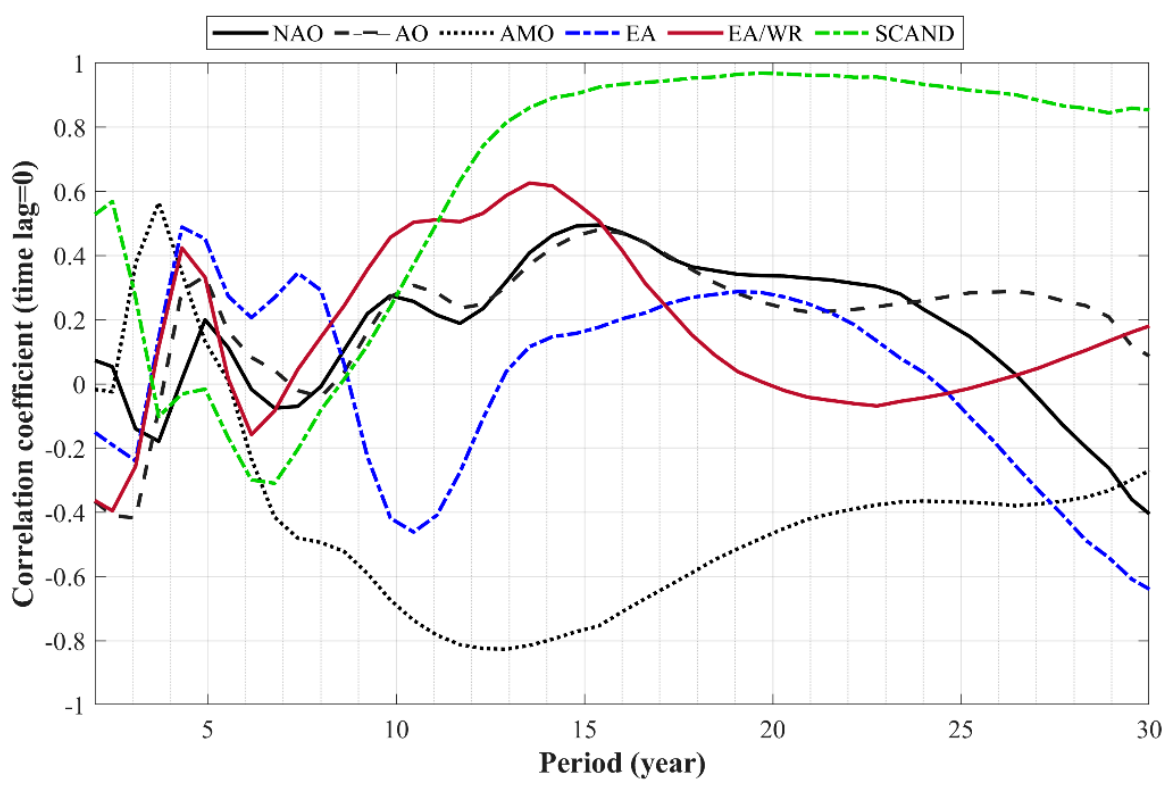

Figure 9. Wavelet correlation coefficients for fluctuations of maximum annual wave height and climate indices: the North Atlantic Oscillation (NAO), the Atlantic Multi-decadal Oscillation (AMO), the East Atlantic Oscillation (EA), the Arctic Oscillation (AO), the East Atlantic-Western Russia (EA/WR) and Scandinavian (SCAND).

Thus, it could be expected that mean inter-annual location of the outer bar crest may vary depending on periods of maximum annual wave fluctuations, which in turn predominantly depend on climate indices the EA and the EA/WR. For example, 9 years periodicity of autumn bar location possibly connected with EA/WR can be seen in Figure 2 for years 2007 and 2016.

\section{Conclusions}

A study has been conducted examining inter- to intra-annual nearshore bar dynamics on the open-coast of Kamchia-Shkorpilovtsi sandy beach at the Bulgarian Black Sea as influenced by regional wave climate, making use of field measurements of seabed morphology, numerically modeled wave data at different time scales and examination of the influence of different telecommunication patterns.

It has been shown that in 2009-2010 on an intra-annual time scale the cross-shore bar (crest) migration followed a certain repetitive seasonal pattern, mainly determined by nonlinear transformation of waves in the coastal zone. During summers, the bar retained its stability farthermost off the shore due to weakly non-linear and low-energy wave regimes. At the same time, the most active in the view of crest displacements are autumn-winter and winter-spring periods in both years, as closest to the shore the outer bar was in winter with minor seaward and shoreward shifts near its reference location. It has been revealed that highly non-linear wave regimes and scenarios of waves transformation are responsible for cross-shore bar migration having wave steepness $>0.03$, significant height over $1 \mathrm{~m}$ and peak period more than $6 \mathrm{~s}$. Even though these threshold values were determined based on hindcast monthly average data their validity has been supported by recent scientific studies at the site, as drawing of more precise thresholds could be secured by regular wave and beach profile measurements and analysis. Furthermore, the results on the influence of storms on the bar migration revealed that direction of crest displacement primarily depends on the wave period, the duration of wave conditions with Hs/Lp > 0.04, angle of wave incidence and total duration of storms. Thus, among the studied storms having rather similar average significant heights, those moving the outer bar seaward had longer periods $(7.2 \mathrm{~s})$, twice as long duration of retained over 0.04 steepness $(121 \mathrm{~h})$, lasted by $\approx 20 \%$ longer and were predominantly approaching from E-ENE, as opposed to storms 
with more oblique angle of incidence NE-ENE displacing the bar shoreward. On annual basis the bar evolution was found the be mainly governed by wave height and storms parameters as angle of approach and duration, since the predominance of oblique wave incidence and longer storm duration in 2009 could be responsible for shoreward shift of bar evolution pattern and increase of depth above its crest. It is appropriate to comment that according to [74] seasonal fluctuations of individual profiles could be as pronounced as alongshore variations of a rhythmic seabed topography, which recently has been confirmed in [15] based on field observations and numerical modeling.

Results concerning the possible connection between the temporal periodicity of Q99Hs and variability of the climatic indices showed that for all time spans, the regional wave climate would be most influenced by the EA and the EA/WR indices. Thus, it is expected that mean inter-annual outer bar location may vary depending on the periods of maximum annual wave height fluctuations, which in turn predominantly depend on the climate indices the EA (4-5, 10-11, 20-30 years) and the EA/WR (2-4, 9-13 years), but also may be affected by the AMO ( 3,13 years), the AO ( 3,15 years) and the SCAND $(2,20-30$ years). The presented results for the first time demonstrate a connection between the climatic indices and the nearshore bar position for the Bulgarian Black Sea coast.

Author Contributions: Writing of the paper, data processing and analysis, visualization of results, N.A.; Article main idea, analysis of climate change and teleconnection patterns, visualization of results, preparation and writing of one section of the paper, Y.S.; SWAN modelling, hindcast data processing and analysis, N.V.; XBeach modelling, experimental data processing and analysis, visualization of results, P.E.; Analysis of climate change and teleconnection patterns, S.K. All authors contributed to interpretation of results, provided critical feedback and helped shape the research. All authors participated in field experiments on the study site. All authors have read and agreed to the published version of the manuscript.

Funding: This research was partly funded by RFBR, grant number 20-55-46005.

Institutional Review Board Statement: Not applicable.

Informed Consent Statement: Not applicable.

Data Availability Statement: Not applicable.

Acknowledgments: This research was supported by 'National Geo-information Center for monitoring, evaluation and forecasting of natural and anthropogenic risks and disasters' within the Program 'National Roadmap for Scientific Infrastructure (2017-2023)' of Republic of Bulgaria, Contract № ДО1-282/17.12.2019; The research was also performed in the framework of Russian Federation state assignment theme № 0128-2021-0004.

Conflicts of Interest: The authors declare no conflict of interest.

\section{References}

1. Plant, N.G.; Holman, R.A.; Freilich, M.H. A simple model for inter-annual sandbar behavior. J. Geophys. Res. 1999, 104, 15755-15776. [CrossRef]

2. O'Hare, T.J.; Huntley, D.A. Bar formation due to wave groups and associated long waves. Mar. Geol. 1994, 116, 313-325. [CrossRef]

3. Wijnberg, K.M.; Kroon, A. Barred beaches. Geomorphology 2002, 48, 103-120. [CrossRef]

4. Dyhr-Nielsen, M.; Sorensen, T. Some sand transport phenomena on coasts with bars. In Proceedings of the 12th International Conference on Coastal Engineering, Washington, DC, USA, 13-18 September 1970; pp. 855-866. [CrossRef]

5. Sallenger, A.H.; Howd, P.A. Nearshore bars and the breakpoint hypothesis. Coast. Eng. 1989, 12, 301-313. [CrossRef]

6. Roelvink, J.A. Surf Beat and its Effect on Cross-Shore Profiles. Ph.D. Thesis, Delft University of Technology, Delft, The Netherlands, 1993; 150p. Available online: http:/ / resolver.tudelft.nl/uuid:160325cb-e1d2-46ec-855e-4626dc4ab754 (accessed on 7 May 2021).

7. Ruessink, B.G. Infra-Gravity Waves in a Dissipative Multiple Bar System. Ph.D. Thesis, Utrecht University, Utrecht, The Netherlands, 1998; 254p.

8. Boczar-Karakiewicz, B.; Davidson-Arnott, R.G.D. Nearshore bar formation by non-linear wave processes-A comparison of model results and field data. Mar. Geol. 1987, 77, 287-304. [CrossRef]

9. Falques, A.; Montoto, A.; Iranzo, V. Bed-flow instability of the longshore current. Cont. Shelf Res. 1996, 16, 1927-1964. [CrossRef] 
10. Larson, M.; Kraus, N.C. Analysis of Cross-Shore Movement of Natural Longshore Bars and Material Placed to Create Longshore Bars; Technical Report DRP-92-5; U.S. Army Engineer Waterways Experiment Station: Vicksburg, MS, USA, 1992; p. 116. Available online: http:/ / resolver.tudelft.nl/uuid:72cb2f64-5ad7-4e7f-9a15-2a778eab1d9e (accessed on 7 May 2021).

11. Yuhi, M.; Matsuyama, M.; Hayakawa, K. Sandbar migration and shoreline change on the Chirihama Coast, Japan. J. Mar. Sci. Eng. 2016, 4, 40. [CrossRef]

12. Ruessink, B.G.; Ranasinghe, R. Beaches. In Coastal Environments $\mathcal{E}$ Global Change, 1st ed.; Masselink, G., Gehrels, R., Eds.; John Wiley \& Sons, Ltd.: Chichester, UK, 2015; pp. 149-177.

13. Walstra, D.J.R. On the anatomy of nearshore sandbars: A systematic exposition of inter-annual sandbar dynamics. Doctoral Thesis, Delft University of Technology, Delft, The Netherlands, 2016; 138p. [CrossRef]

14. Ribas, F.; Albert Falqués, A.; Garnier, R. Nearshore sand bars. In Atlas of Bedforms in the Western Mediterranean; Guillén, J., Acosta-Yepes, J., Chiocci, F.L., Palanques, A., Eds.; Springer International Publishing: Cham, Switzerland, 2017; Chapter 13, pp. 73-79.

15. Ruggiero, P.; Walstra, D.J.R.; Gelfenbaum, G.; van Ormondt, M. Seasonal-scale nearshore morphological evolution: Field observations and numerical modeling. Coast. Eng. 2009, 56, 1153-1172. [CrossRef]

16. Shepard, F.P. Beach Cycles in Southern California. Beach Erosion Board, Technical Memorandum; Beach Erosion Board Engineer Research and Development Center: Vicksburg, MS, USA, 1950; Volume 20, p. 31. Available online: https://hdl.handle.net/11681/3369 (accessed on 7 May 2021).

17. Dubarbier, B.; Castelle, B.; Ruessink, G.; Marieu, V. Mechanisms controlling the complete accretionary beach state sequence. Geophys. Res. 2017, 44, 5645-5654. [CrossRef]

18. Ruessink, B.G.; Kuriyama, Y.; Reniers, A.J.H.M.; Roelvink, J.A.; Walstra, J.A. Modeling cross-shore sandbar behavior on the timescales of weeks. J. Geophys. Res. 2007, 112. [CrossRef]

19. Grasso, F.; Michallet, H.; Certain, R.; Barthélemy, E. Experimental flume simulation of sandbar dynamics. J. Coast. Res. 2009, 56, 54-58. Available online: https://www.jstor.org/stable/25737536 (accessed on 7 May 2020).

20. Walstra, D.J.R.; Ruggiero, P.; Lesser, G.; Gelfenbaum, G. Modeling nearshore morphological evolution at seasonal scale. In Proceedings of the Fifth Coastal Dynamics International Conference, Barcelona, Spain, 4-8 April 2005. [CrossRef]

21. Ruessink, B.G.; Pape, L.; Turner, I.L. Daily to interannual cross-shore sandbar migration: Observations from a multiple sandbar system. Cont. Shelf Res. 2009, 29, 1663-1677. [CrossRef]

22. Cheng, J. Multiple scales of beach morphodynamic processes: Measurements and modelling. Ph.D. Thesis, University of South Florida, Tampa, FL, USA, 2015; p. 198. Available online: https://scholarcommons.usf.edu/etd/5924 (accessed on 7 May 2021).

23. Vidal-Ruiz, J.A.; de Alegría-Arzaburu, A.R. An annual cycle of sandbar migration on an intermediate meso-tidal beach: Ensenada, Mexico. In Proceedings of the Coastal Dynamics 2017, Helsingør, Denmark, 12-16 June 2017; pp. 575-585, Paper No. 223.

24. Vidal-Ruiz, J.A.; de Alegría-Arzaburu, A.R. Variability of sandbar morphometrics over three seasonal cycles on a single-barred beach. Geomorphology 2019, 333, 61-72. [CrossRef]

25. Bergsma, E.W.J.; Conley, D.C.; Davidson, M.A.; O’Hare, T.J.; Almar, R. Storm Event to Seasonal Evolution of Nearshore Bathymetry Derived from Shore-Based Video Imagery. Remote Sens. 2019, 11, 519. [CrossRef]

26. Prusak, Z.; Nikolov, H. Analysis of type-profiles in the conditions of the coastal zones of Poland and Bulgaria. Proc. IO-BAS 1992, 1, 65-73. (In Bulgarian)

27. Trifonova, E.; Valchev, N.; Andreeva, N.; Eftimova, P. Critical storm thresholds for morphological changes in the western Black Sea coastal zone. Geomorphology 2012, 143-144, 81-94. [CrossRef]

28. Nikolov, H. Thickness of the eroded layer and tendencies in beach profile changes in front of seaside resorts 'Albena', 'Golden sands' and 'Drujba'. Oceanology 1981, 8, 54-60. (In Bulgarian)

29. Keremedchiev, S. Seasonal fluctuations of beach pr ofiles. Oceanology 1985, 14, 63-74. (In Bulgarian)

30. Nikolov, H. Influence of wave steepness and bottom slope on the short-term deformations of the underwater bottom slope. In Interaction of the Atmosphere, Hydrosphere and Lithosphere in the Nearshore Zone-Results of the International Experiment 'Kamchia 78', 1st ed.; Belberov, Z., Antsyferov, S., Zahariev, V., Zats, V., Pykhov, N., Eds.; Publishing House of the Bulgarian Academy of Sciences: Sofia, Bulgaria, 1982; pp. 205-212. (In Bulgarian)

31. Antsyferov, S.; Pykhov, N.; Dachev, V. Dynamics of suspended sediments. In Dynamical Processes in Coastal Regions, 1st ed.; Antsyferov, S., Belberov, Z., Massel, S., Eds.; Publishing house of the Bulgarian Academy of Sciences: Sofia, Bulgaria, 1990; pp. 157-159.

32. Trifonova, E.; Valchev, N.; Andreeva, N.; Eftimova, P.; Kotsev, I. Measurements and analysis of storm induced short-term morphological changes in the western Black Sea. J. Coast. Res. 2011, 1, 149-154. Available online: https://www.jstor.org/stable/ 26482151 (accessed on 7 May 2021).

33. Eftimova, P.; Trifonova, E.; Valchev, N.; Andreeva, N. Beach erosion caused by storms. Morphological model set up and calibration. In Proceedings of the 11th International Conference on Marine Sciences and technologies—Black Sea'2012, Varna, Bulgaria, 4-6 October 2012; pp. 69-73.

34. Valchev, N.; Andreeva, N.; Eftimova, P.; Trifonova, E. Prototype of early warning system for coastal storm hazard (Bulgarian Black Sea coast). Compt. Rend. Acad. Bulg. Sci. 2014, 67, 971-978.

35. Valchev, N.; Eftimova, P.; Andreeva, N. Implementation and validation of a multi-domain coastal hazard forecasting system in an open bay. Coast. Eng. 2018, 134, 212-228. [CrossRef] 
36. Walstra, D.-J.R.; Wesselman, D.A.; Van der Deijl, E.C.; Ruessink, G. On the intersite variability in inter-annual nearshore sandbar cycles. J. Mar. Sci. Eng. 2016, 4, 15. [CrossRef]

37. Shand, R.D.; Bailey, D.G.; Shephard, M.J. An inter-site comparison of net offshore bar migration characteristics and environmental conditions. J. Coast. Res. 1999, 15, 750-765.

38. Ruessink, B.G.; Kroon, A. The behavior of a multiple bar system in the nearshore zone of Terschelling: 1965-1993. Mar. Geol. 1994, 121, 187-197. [CrossRef]

39. Wijnberg, K.M.; Terwindt, J.H.J. Extracting decadal morphological behavior from high-resolution, long-term bathymetric surveys along the Holland coast using Eigen function analysis. Mar. Geol. 1995, 126, 301-330. [CrossRef]

40. Ruessink, B.G.; Terwindt, J.H.J. The behavior of nearshore bars on the time scale of years: A conceptual model. Mar. Geol. 2000, 163, 289-302. [CrossRef]

41. Masselink, G.; Austin, M.; Scott, T.; Poate, T.; Russell, P. Role of wave forcing, storms and NAO in outer bar dynamics on a high-energy, macro-tidal beach. Geomorphology 2014, 226, 76-93. [CrossRef]

42. Saprykina, Y.; Kuznetsov, S.; Valchev, N. Multi-decadal fluctuations of storminess of the Black Sea due to teleconnection patterns on the base of modelling and field wave data. In Lecture Notes in Civil Engineering, Proceedings of the Fourth International Conference in Ocean Engineering (ICOE2018), Chennai, India, 18-21 February 2018; Murali, K., Sriram, V., Samad, A., Saha, N., Eds.; Springer: Singapore, 2019; Volume 22, pp. 773-781. [CrossRef]

43. D-Maps: Free Maps. Available online: https:/ / d-maps.com (accessed on 7 May 2021).

44. Maxar Technologies-High-Resolution Satellite Imagery, Westminster, CO, USA. Available online: https://www.maxar.com (accessed on 7 May 2021).

45. Ostrowski, R.; Pruszak, Z.; Skaja, M.; Szmytkiewicz, M.; Trifonova, E.; Keremedchiev, S.; Andreeva, N. Hydrodynamics and lithodynamics of dissipative and reflective shores in view of field investigations. Arch. Hydro-Eng. Environ. Mech. 2010, 57, 219-241.

46. Valchev, N.; Davidan, I.; Belberov, Z.; Palazov, A.; Valcheva, N. Hindcasting and assessment of the western Black sea wind and wave climate. J. Environ. Prot. Ecol. 2010, 11, 1001-1012.

47. Belberov, Z.; Antsyferov, S. Research station conditions and organization of experiments. In Dynamical Processes in Coastal Regions: Results of Kamchia International Project, 1st ed.; Popov, V., Antsyferov, S., Belberov, Z., Massel, S., Eds.; Publishing House of the Bulgarian Academy of Sciences: Sofia, Bulgaria, 1990; pp. 14-22.

48. Davidan, I.; Belberov, Z.; Aubrey, D.; Lavrenov, I. Transformation of wind wave spectral parameters according to the Black sea international experiment. Proc. IO-BAS 2005, 5, 51-64.

49. Saprykina, Y.; Kuznetsov, S.; Andreeva, N.; Shtremel, M. Scenarios of non-linear wave transformation in the coastal zone. Oceanology 2013, 53, 422-431. [CrossRef]

50. Kuznetsova, O.; Saprykina, Y.; Shtremel, M.; Kuznetsov, S.; Korzinin, D.; Trifonova, E.; Andreeva, N.; Valchev, N.; Prodanov, B.; Eftimova, P.; et al. Dynamics of sandy beach in dependence on wave parameters. In Maritime Transportation and Harvesting of Sea Resources, Proceedings of the 17th International Congress of the International Maritime Association of the Mediterranean (IMAM'2017), Lisbon, Portugal, 9-11 October 2017; Guedes Soares, C., Teixeira, A.P., Eds.; Taylor \& Francis Group: London, UK, 2017; Volume 2, pp. 1075-1079.

51. Nikolov, H.; Pykhov, N. Brief deformations along the profile of the underwater coastal slope during storm. In Interaction of the Atmosphere, Hydrosphere and Lithosphere in the Nearshore Zone. Results of the International Experiment 'Kamchia 77', 1st ed.; Belberov, Z., Zahariev, V., Kuznetsov, O., Massel, S., Pykhov, N., Rojdestvensky, A., Filyushkin, B., Eds.; Publishing House of the Bulgarian Academy of Sciences: Sofia, Bulgaria, 1980; pp. 229-237. (In Russian)

52. U.S. Army Corps of Engineers. Coastal Engineering Manual, 18th ed.; U.S. Army Corps of Engineers: Washington, DC, USA, 2006; Electronic; ISBN 978-1-60119-026-0. Available online: http:/ / app.knovel.com/hotlink/toc/id:kpCEM0000P/coastal-engineeringmanual (accessed on 7 May 2021).

53. The SWAN Team. SWAN User Manual; Delft University of Technology: Delft, The Netherlands, 2016.

54. Feser, F.; Weisse, R. Multi-decadal atmospheric modeling for Europe yields multi-purpose data. EOS Trans. AGU 2001, 82, 305-310. [CrossRef]

55. Yang, F.; Pan, H.; Krueger, S.K.; Moorthi, S.; Lord, S.J. Evaluation of the NCEP global forecast system at the arm SGP site. Mon. Weather Rev. 2006, 134, 3668-3690. [CrossRef]

56. Valchev, N.; Trifonova, E.; Andreeva, N. Past and recent trends in the western Black Sea storminess. Nat. Hazards Earth Syst. Sci. 2012, 12, 961-977. [CrossRef]

57. Roelvink, D.; Reniers, A.; van Dongeren, A.; van Thiel de Vries, J.; McCall, R.; Lescinski, J. Modelling storm impacts on beaches, dunes and barrier islands. Coast. Eng. 2009, 56, 1133-1152. [CrossRef]

58. Vieira, B.F.V.; Pinho, J.L.S.; Barros, J.A.O.; Antunes do Carmo, J.S. Hydrodynamics and Morphodynamics Performance Assessment of Three Coastal Protection Structures. J. Mar. Sci. Eng. 2020, 8, 175. [CrossRef]

59. Castelle, B.; Bonneton, P.; Dupuis, H.; Sénéchal, N. Double bar beach dynamics on the high-energy meso-macrotidal French Aquitanian Coast: A review. Mar. Geol. 2007, 245, 141-159. [CrossRef]

60. Saprykina, Y. The influence of wave non-linearity on cross-shore sediment transport in coastal zone: Experimental investigations. Appl. Sci. 2020, 10, 4087. [CrossRef] 
61. Korzinin, D.; Shtremel, M. Deformation of coastal profile during different storm phases. In Proceedings of the 36th International Conference on Coastal Engineering, Baltimore, MD, USA, 30 July-3 August 2018; Volume 1, p. 43. [CrossRef]

62. Saprykina, Y.; Kuznetsova, O. Influence of wave transformation processes on evolution of underwater beach profile. In Proceedings of the 36th International Conference on Coastal Engineering, Baltimore, MD, USA, 30 July-3 August 2018; Volume 1, p. 65. [CrossRef]

63. Saprykina, Y.V.; Shtremel, M.N.; Kuznetsov, S.Y. On the possibility of bi-phase parametrization for wave transformation in the coastal zone. Oceanology 2017, 57, 253-264. [CrossRef]

64. Saprykina, Y.V.; Kuznetsov, S.Y.; Divinskii, B.V. Influence of processes of nonlinear transformations of waves in the coastal zone on the height of breaking waves. Oceanology 2017, 57, 383-393. [CrossRef]

65. Longinov, V.V. Coastal Zone Dynamics in Tideless Seas; The USSR Academy of Sciences Publisher House: Moscow, Russia, 1963; p. 379. (In Russian)

66. Kuznetsova, O.; Saprykina, Y.; Divinsky, B. Underwater barred beach profile transformation under different wave conditions. In Coastal erosion and dynamical processes in the nearshore zone, Proceedings of the Materials of XXVI International Coastal Conference Managing Risks to Coastal Regions and Communities in a Changing World, Saint-Petersburg, Russia, 22-27 August 2016; Academus Publishing: Redwood, CA, USA, 2016. [CrossRef]

67. Kuznetsova, O.; Saprykina, Y. Intra-annual storm deformations on sandy beach by an example of Kamchia-Shkorpilovtsi coast (Black Sea, Bulgaria). Proc. Geom. 2017, 10, 435-444. (In Russian)

68. Saprykina, Y.V.; Kuznetsov, S.Y. Methods of analysis of nonstationary variability of wave climate of Black Sea. Phys. Oceanogr. 2018, 4, 156-164. [CrossRef]

69. Polonsky, A.; Evstigneev, V.; Naumova, V.; Voskresenskaya, E. Low-frequency variability of storms in the northern Black Sea and associated processes in the ocean-atmosphere system. Reg. Environ. Chang. 2014, 14, 1861-1871. [CrossRef]

70. Zăinescu, F.I.; Tătui, F.; Valchev, N.N.; Vespremeanu-Stroe, A. Storm climate on the Danube delta coast: Evidence of recent storminess change and links with large-scale teleconnection patterns. Nat. Hazards 2017, 87, 599-621. [CrossRef]

71. Saprykina, Y.; Shtremel, M.; Aydoğan, B.; Ayat Aydoğan, B. Variability of the nearshore wave climate in the eastern part of the Black Sea. Pure Appl. Geoph. 2019, 176, 3757-3768. [CrossRef]

72. Saprykina, Y.; Kuznetsov, S. Analysis of the variability of wave energy due to climate changes on the example of the Black Sea. Energies 2018, 11, 2020. [CrossRef]

73. National Oceanic and Atmospheric Administration of U.S.A. Available online: https:/ /www.cpc.ncep.noaa.gov (accessed on 23 January 2021).

74. Sonu, C. Three-dimensional beach changes. J. Geol. 1973, 81, 42-64. Available online: https://www.jstor.org/stable/30060693 (accessed on 7 May 2021). [CrossRef] 